\title{
Management Service of University Library Based on Modern Management Science Theory
}

\author{
Dongqing $\mathrm{Cai}^{\text {a }}$ \\ Hua Zhong University of Science and Technology Library, Wu Han 430074, China. \\ a kld512@163.com
}

Keywords: Library management; university library; innovation practice; innovation theory.

\begin{abstract}
To make the library more adapt to the development of modern society, the management of university library in China was taken as the object. According to the current characteristics of library management and combined with the actual situation of the management of university library in China, the theory and method of modern management science were applied. On the basis of the theoretical results of researches done by domestic and foreign scholars, innovation theory of university library management in China under the new situation was established. The results showed that this innovative research on university library management was helpful for the current university library management innovation practice. To sum up, the exploration helps the university library to give full play to its educational function and provide better services for the school students.
\end{abstract}

\section{Introduction}

As the basic source of obtaining literature information between teachers and students in colleges and universities, university library has been playing an important role in the study for college students. With the continuous development of network information technology, it is a topic worth paying attention to how the university libraries to better and faster develop in the current social background [1]. In the long run development practice, there are many innovative management concepts [2], but there are few researches on the library management concept at a certain stage [3]. Since the new world, the library's innovation idea is mainly people-centred to explore how to protect the rights of people to enjoy library services. The idea produced is driving the development of libraries [4]. The traditional library implements the closed management and the management structure is linear so that it cannot be flexibly mobilized. The quality of librarians is low and such management is no longer suitable for the current social development $[5,6]$.

Through literature research methods, we analyse the shortcomings of the library management and obtain the necessity of the management innovation of university library. Based on the modern management science theory, we summarize the essential characteristics of modern library management innovation. Through the example of Tsinghua University library innovation practice, we put forward some measures to manage innovation, so as to change the backward status of library management and provide better service for the teaching and scientific research.

\section{Methodology}

The innovation management of library management in colleges and universities is a complicated problem. This paper introduces the research knowledge, methods, techniques and achievements of different fields in the study of this problem in the university library. The research methods mainly include: qualitative analysis and quantitative analysis method, case study method, comparative analysis method, and empirical research method.

In library research, the commonly used method is qualitative analysis method. Through this method, we can understand the nature of the object, the connection with the external and the related changes. However, the qualitative analysis is far from enough. At this time, it is necessary to use the quantitative analysis method. On the basis of qualitative analysis, this paper has added the method of quantitative analysis to analyse the problem of library management. In this paper, case study is adopted and cases are introduced in many studies, and the case is analysed and discussed. The 
comparative analysis methods mainly include vertical comparison and horizontal comparison. Vertical comparison refers to the comparison of the same thing in different historical periods, while horizontal comparison is a comparison between different countries or regions of the same thing. In this article, some parts of the study used the method of comparative study because of the problem prof requirements. In the process of research, the empirical research method is applied, and the practice of university management innovation is applied as an example to verify the correctness and effectiveness of the theoretical method adopted in this study.

\section{Results and Discussion}

\subsection{Necessity of Innovation in the Management of University Library}

With the advent of the information age, the working idea and way of university library are gradually transforming. First of all, the library work thoughts transform from closed management to open management of information network; secondly, the library's collection transfers from the physical collection to the physical and virtual collections coexisting; next, the work object transforms from a single media into multimedia coexisting; finally, the depth of the library information service has changed. In today's network environment, people need deeper information services. In this service, the idea of "user-centred" is the consensus of most libraries.

Through the investigation, we find that there are a lot of problems in the current library, as shown in Figure 1. The development of the society requires the university library to carry out innovation. Since the end of twentieth Century, the institutions, scale, level and efficiency of our universities have changed greatly due to the merger, enrolment expansion and "strong school". In order to have its own development space in the fierce competition, the university needs to promote the development of the library together with its own development.

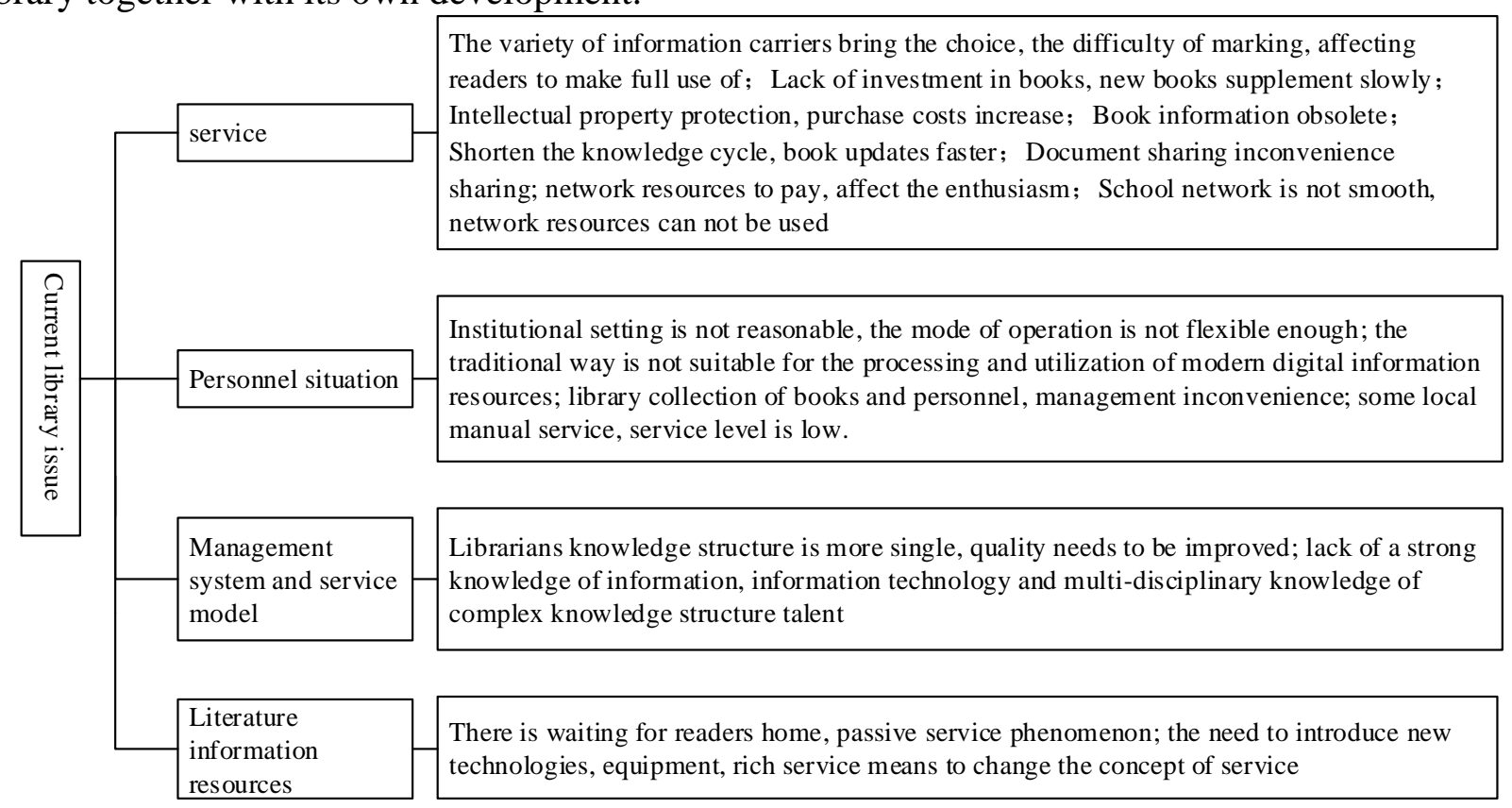

Figure. 1. Current library problems

\subsection{Essence and Characteristics of the Management Innovation of the University Library}

The so-called management innovation is the process, based on the creation and mastery of new scientific management knowledge, to actively adapt to the external environment and improve the new changes and combinations of all elements in quality. The library's innovation should include at least the following aspects: firstly, there is a new development idea and its supporting organization; the second is to generate new management means and methods; the third is to design new management mechanisms; and the four is to make the system innovated. To carry on the innovation of university library, we should, based on understanding the internal structure and connections, accurately grasp the overall optimization principle and method, make the management of library scientific, and ultimately achieve the development of the library to adapt to social development, matching with the 
changing demands of readers. Facing the complex and changeable environment and changing rapidly competition of knowledge economy, library begin adjusting various resources, make a new exploration and establish new theory, system and method, which makes the management innovation of university library has many aspects, all-round, full-participation, continuous and unrepeated properties.

\subsection{Approaches for Innovation of University Library Management Under the New Situation}

In the new situation, there are many ways to innovate the management of university library, which is summarized as Figure 2. Library management follows the purpose of management, that is, the basis and core of library management thought is the principle of utility and benefit. In order to realize the principle of utility and benefit, we must change the traditional management method and make a comprehensive adjustment to the concept and structure. Management ideas must be changed. We should transform from general construction to characteristic construction, transform from emphasizing ownership to focusing on access, innovate in the way of library development, and innovate in library's position and function cognition.

For the innovation of the management mechanism of the university library, we divide it into the reorganization of the external mechanism and the internal mechanism. The innovation of external mechanism includes export-oriented information management mechanism, network-oriented information flow centralized management and material flow decentralized mechanism. Coopering with information technology innovation department, an interactive mechanism with continuously improved automation technology is established. The innovation of internal mechanism includes the establishment of a management mechanism for the user's rapid response and the reorganization of the new business model, which is automation-centred. The measurements carried out in institutional innovation resources in the university library include to make system resources innovative, construct innovative system, rationally allocate system form, make library operational mechanism innovative, provide financial support for university library, improve the personnel management of university library and perform innovation of reader service system. Through the innovation of these mechanisms, we can achieve the creation of a reader-centred system.

The traditional organizational structure of library is linear. The weakness of this structure is the separation and closure of functions. In order to make the operation of the organization more flexible and open, we need to make the organizational structure innovated. We need to make plenty of internal organizational structure, create business process, implement the total branch system and construct learning organization. As an important social organization, the library must adapt to the trend of the society and go in the forefront of the times.

In the library, people are the most animate and most active factors, so the management of library personnel is also one of the important contents of library management. Human resource is a kind of wealth, so we need to make a reasonable allocation of it. The current library human resource management is restricted by the traditional personnel management concept and affected by internal and external adverse environment. As a result, it lacks the using environment and development space for high-level personnel and the loss of human resources is serious. In the human resource management, we should establish a new concept of human resource as the most important resources of modern library, do a good job of planning the development of human resources management and establish mechanisms for the introduction of excellent talents. Moreover, we should optimize the internal and external environment, realize human resources echelon development, achieve the humanized management, establish a scientific incentive mechanism and pay attention to the training of innovative talents.

With the development of Internet, information diversity, resource sharing and development of multimedia technology, the knowledge structure has undergone great changes and the user demand has become all-round, comprehensive, integrated and efficient. As a result, we need to conduct innovation of the information resource management of university library. We should strengthen the development and construction of network information resources, make great efforts to build the database of characteristic collection, and establish a regional resource sharing system. 
To innovate the service of university library, we can meet the changing needs of readers. In this regard, we need to establish a networked integrated service system, develop information navigation on the Internet, and expand the service function of libraries.

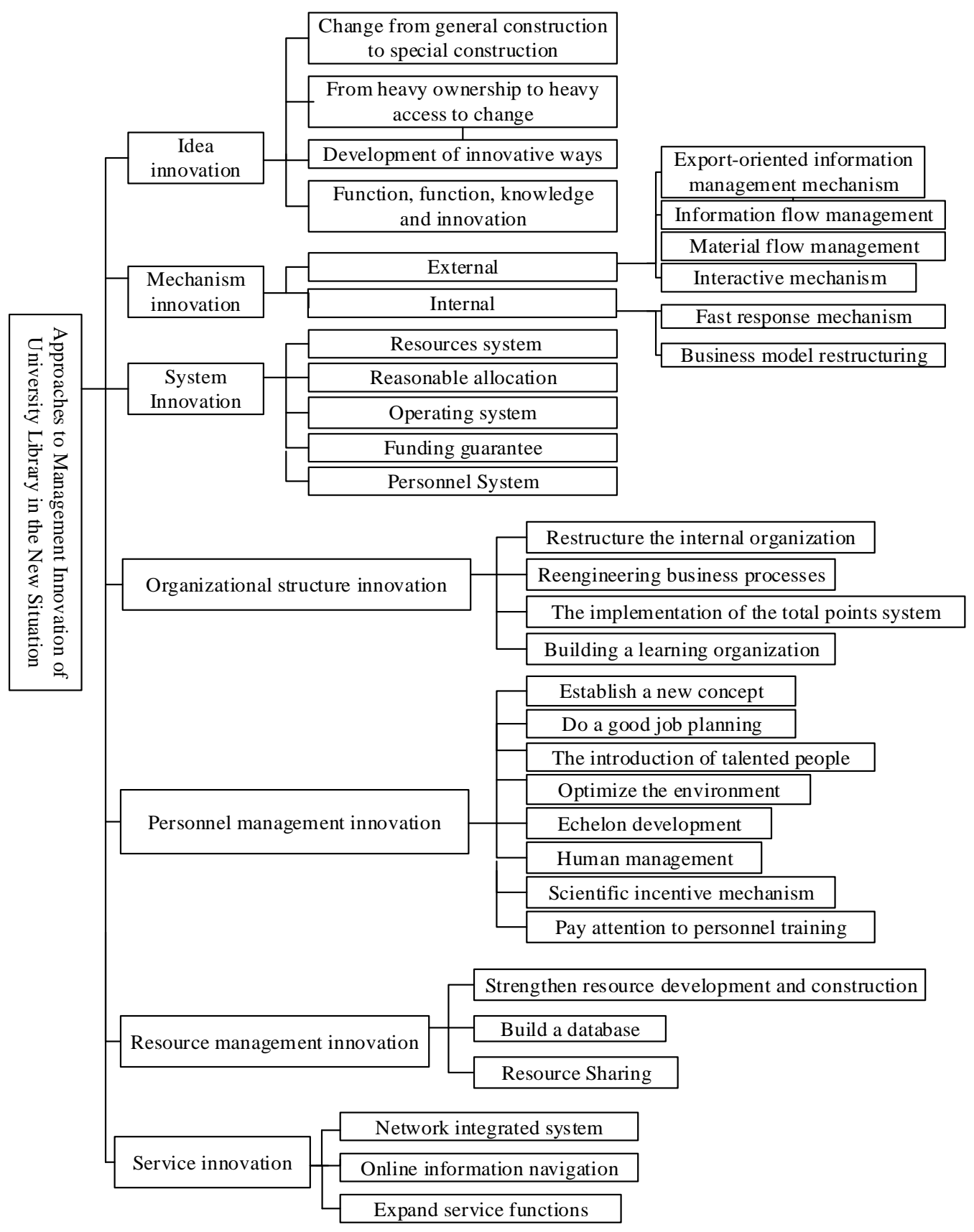

Figure. 2. Approaches for management innovation

\subsection{Case Study on Innovation of University Library Management}

Taking Tsinghua University as an example, we introduce the practice of library management innovation. Figure 3 shows the innovations carried out by the Tsinghua University library. Through this case, we recognize the library management innovation from the concept, lay the material foundation of information resources and provide a high level of service. It is necessary to change from emphasizing possession to focusing on access and from closed network to information network and take the readers as the centre to carry out the work. Only in this way can the development of library be active and the sustainable development of the library be realized. 


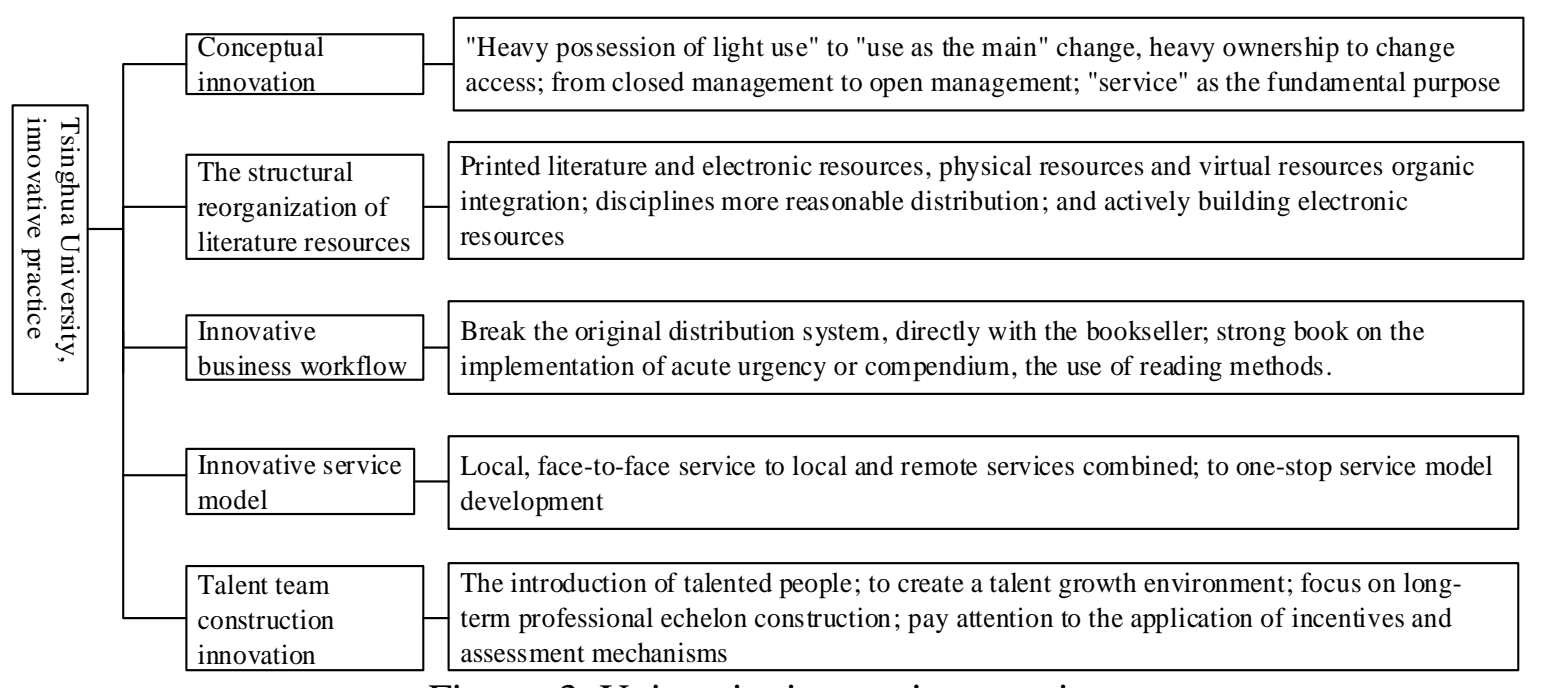

Figure. 3. University innovation practice

\section{Conclusion}

This study analyses the impact of networking on library resources, organizations and readers, and analyses the current situation and existing problems of university library management. On the basis of a large number of literature journals at home and abroad, around the university library management theory and practice, the implementation approaches for management innovation are proposed from various aspects, including the university library management thought, concept innovation, management mechanism, management system innovation, personnel management innovation, organization structure and business process management innovation, information resources management innovation, service innovation and other aspects. Based on the case of Tsinghua University library management innovation, the importance of library management is recognized and the important enlightenment of library management innovation is obtained. In general, only the continuous self-improvement and self-innovation can the library follow the pace of the society, make common progress and develop together.

\section{Acknowledgements}

The authors acknowledge the National Natural Science Foundation of China (Grant: 111578109), the National Natural Science Foundation of China (Grant: 11111121005).

\section{References}

[1] Smith B J. The case for international collaboration in academic library management, human resources and staff development. Ifla Journal, 2015, 41(2), pp. 140-152.

[2] P. H, Shylesh S, Aithal P S. Information Technology Innovations in Library Management: A Case of SIMS. Social Science Electronic Publishing, 2016, 1(1), pp. 657-676.

[3] Madhusudhan M, Singh V. Integrated library management systems: Comparative analysis of Koha, Libsys, NewGenLib, and Virtua. Electronic Library, 2016, 34(2), pp. 223-249.

[4] Shoman N T, Skutnik S E. Development of modern CANDU PHWR cross-section libraries for SCALE. Nuclear Engineering \& Design, 2016, 302, pp. 56-67.

[5] Lara K. The library's role in the management and funding of open access publishing. Learned Publishing, 2016, 28(1), pp. 4-8.

[6] Johnson K G, Ireland J L. Embracing Changing Technology and New Technical Services Workflows in Migrating to a Next-Generation Library Management System. Serials Librarian, 2017, 72(1-4), pp. 65-72. 